The Bangladesh Veterinarian (2013) 30(2) : 46 - 53

\title{
General anaesthesia of indigenous pigs in Bangladesh
}

\author{
MS Rana, MM Rahman*, UK Rima ${ }^{1}$ and NS Juyena \\ Department of Surgery and Obstetrics, Faculty of Veterinary Science, Bangladesh \\ Agricultural University, Mymensingh-2202, Bangladesh
}

\begin{abstract}
Anaesthetic trials were conducted with propofol (P), xylazine-propofol (XP), xylazineketamine $(\mathrm{XK})$, xylazine-thiopentone $(\mathrm{XT})$ in 16 healthy indigenous pigs. Respiration rate decreased significantly $(\mathrm{P}<0.01)$ five minutes after induction, and during maximum depth of anaesthesia, and had not returned to control value after recovery from anaesthesia with all anaesthetic combinations. Heart rate with $\mathrm{P}$ increased significantly $(\mathrm{P}<0.01)$ five minutes after induction, whereas it decreased significantly $(\mathrm{P}<0.01)$ with $\mathrm{XP}$, $\mathrm{XK}$ and $\mathrm{XT}$ during anaesthesia and remained below the normal range after recovery from anaesthesia except after XP. In all anaesthetic sessions, rectal temperature decreased significantly $(\mathrm{P}<0.01)$ in all stages of anaesthesia: after recovery the rectal temperature almost returned to control value in $\mathrm{P}$ and $\mathrm{XP}$. Slight to moderate salivation was observed in all pigs with $\mathrm{P}$ and $\mathrm{XP}$. It is suggested that $\mathrm{P}$ and $\mathrm{XP}$ combination seems to be suitable for general anaesthesia in pigs, but XP is more suitable. (Bangl. vet. 2013. Vol. 30, No. 2, $46-53)$
\end{abstract}

\section{Introduction}

Improper handling of pigs causes considerable stress (Hau and Van Hoosier, 2003; Madrigal et al., 2006). Pigs are often given local or regional anaesthesia, sedation or general anaesthesia (Ko et al., 1993). Anaesthesia is frequently required for therapeutic procedures and experimental models (Toyama et al., 2004; Wessler et al., 2011) and major operative procedures (Arras et al., 2001; Caulkett, 2003). The responses to anaesthetic agents are highly variable (Sessler, 1994; Gross, 2009; Schifilliti, 2010). Xylazine, a2-adrenergic agonist has been used routinely as a premedicant in pigs (Pypendop et al., 1996; Lee et al., 2010). Ketamine hydrochloride is frequently used for sedation, induction of anaesthesia and analgesia (Ajadi et al., 2008). Xylazine hydrochloride has commonly been used with ketamine hydrochloride for surgical anaesthesia in pigs (Gaertner et al., 2008).

Thiopentone sodium is an intravenous agent used for induction of anaesthesia prior to inhalation anaesthesia or as a sole agent for minor procedures in animals (Riebold et al., 1995; Tacheci et al., 2013). The combination of thiopentone sodium with xylazine hydrochloride causes a longer recovery time (Hall et al., 2001; Kate and Polly, 2000). Propofol is an intravenous anaesthetic agent, used for anaesthetic induction and maintenance (Glen and Hunter, 1984; Watkins et al., 1987) and measures to monitor

\footnotetext{
1Department of Medicine, Surgery and Obstetrics, Faculty of Veterinary \& Animal Sciences, Hajee Mohammad Danesh Science and Technology University, Dinajpur, Bangladesh

*Corresponding author:- E-mail: miznih@gmail.com
} 
the anaesthetic depth have been reported (Ribeiro et al., 2009; Silva et. al., 2011). Combinations of xylazine hydrochloride and propofol have been used as safe anaesthetic for goats (Amarpal et al., 2002), dogs (Cullen and Reynoldson, 1997; Kim and Jang, 1999), and horses (Mama et al., 1998). However, there is no record of using propofol and its combination to anaesthetize indigenous pigs in Bangladesh. The present study was carried out to investigate the effects of propofol, and combinations of propofol, ketamine hydrochloride and thiopentone sodium with xylazine hydrochloride in pigs.

\section{Materials and Methods}

\section{Experimental animals}

Sixteen anaesthetic sessions were performed in 16 healthy indigenous pigs during January to May, 2013. Age of the pigs ranged from 12 - 16 months and body weight from 12 - $15 \mathrm{~kg}$. The animals were selected randomly regardless of their sex for each anaesthetic session from a nomadic herd. They had access to pasture for 6 - 8 hours a day and had a free access to water. All animals were routinely examined before anaesthesia. The study was conducted at Upazila (sub-district) Veterinary Hospital, Taraganj, Rangpur.

\section{Study design}

The pigs were divided into four groups:

Group-P: This group was treated with propofol alone (Pofol ${ }^{\circledR}$, Popular Infusion Ltd, Bangladesh) $4 \mathrm{mg} / \mathrm{kg}$ body weight, intravenously.

Group-XP: Pigs were treated with xylazine hydrochloride (Xylaxin ${ }^{\circledR}$ Indian Immunologicals Ltd, India) $1.1 \mathrm{mg} / \mathrm{kg}$ body weight, intramuscularly. After five minutes propofol was administered $4 \mathrm{mg} / \mathrm{kg}$ body weight, intravenously.

Group-XK: Xylazine hydrochloride of $1.1 \mathrm{mg} / \mathrm{kg}$ body weight was given intramuscularly and ketamine hydrochloride (G-Ketamine ${ }^{\circledR}$, Gonoshasthaya Pharmaceuticals Ltd., Bangladesh) administered $11 \mathrm{mg} / \mathrm{kg}$ body weight, intramuscularly after five minutes of premedication.

Group-XT: Freshly prepared 5\% thiopentone sodium (G-Thiopental ${ }^{\circledR}$, Gonoshasthaya Pharmaceuticals Ltd, Bangladesh) $8 \mathrm{mg} / \mathrm{kg}$ body weight was given intravenously five minutes after xylazine hydrochloride injection.

\section{Preparation and anaesthesia of animals}

The animals were closely monitored from 72 hours prior to anaesthesia. Thorough clinical examinations were performed. The animals to be anaesthetized were isolated from others and starved for 12 hours. Anaesthesia was performed in the morning when temperature and humidity were lower. 
Monitoring of clinical parameters

Respiratory and heart rates and rectal temperature were monitored five minutes prior to premedication, five minutes after induction of anaesthesia, during maximum depth of anaesthesia and after complete recovery.

Observation of physiological responses

Salivation, lacrimation, urination, defecation, protrusion of tongue and shivering were observed in all pigs during the period of anaesthesia.

\section{Statistical analysis}

Student's paired $t$-test for correlated data was used to analyse clinical parameters to determine whether the changes observed in the test levels significantly differ from control values. Analysis of Variance (ANOVA) in completely randomized design (CRD) was applied to analyse data regarding the parameters. Results were assessed by the Least Significant Difference (LSD) test in "MSTAT" computer program.

\section{Results and Discussion}

The respiration rate decreased significantly $(\mathrm{P}<0.01)$ five minutes after induction, and during maximum depth of anaesthesia, and had not returned to control value even after recovery in groups $\mathrm{XP}, \mathrm{XK}$ and $\mathrm{XT}$. These results correspond with previous studies where respiratory depression was observed with a decrease in tidal volume and respiratory rate (Lumb and Jones, 1996; Murrell, 2007; Thurmon and Smith, 2007; Lee et al., 2010). Ketamine is a potent respiratory depressant (Ramakrishna et al., 1981; Schifilliti, 2010). Xylazine-ketamine anaesthesia decreased respiration rate (More et al., 1993). However, decreased respiration rate might be due to depression of respiratory centres either by xylazine alone or by both xylazine and ketamine. Similarly, thiopentone decreased respiratory rate in sheep (Huang et al., 1997). Moreover, thiopentone decreased respiration rate as a result of depression of central nervous system and reduction of the sensitivity of the respiratory centre to carbon dioxide (Hall et al., 2001). In group $\mathrm{P}$, a significant $(\mathrm{P}<0.01)$ decrease in respiration rate was observed during maximum depth of anaesthesia. This result is similar to Carroll et al. (1998) who reported depression of respiration rate in animals when anaesthetized with propofol.

Table 1. Effects of different anaesthetic agents on respiratory rate in pigs

\begin{tabular}{l|cccc|c}
\hline \multicolumn{1}{c|}{ Groups } & \multicolumn{4}{c}{ Respiratory rate/minute } \\
\cline { 2 - 4 } & $\begin{array}{c}5 \text { min prior to } \\
\text { premedication }\end{array}$ & $\begin{array}{c}5 \text { min after induction } \\
\text { of anaesthesia }\end{array}$ & $\begin{array}{c}\text { During maximum } \\
\text { depth of anaesthesia }\end{array}$ & $\begin{array}{c}\text { After recovery from } \\
\text { anaesthesia }\end{array}$ \\
P & $28.5 \pm 0.8$ & $24.0 \pm 0.7^{*}$ & $21.0 \pm 0.4^{* *}$ & $26.3 \pm 0.9^{* *}$ \\
XP & $29.5 \pm 1.3$ & $20.5 \pm 1.2^{* *}$ & $16.5 \pm 1.0^{* *}$ & $20.5 \pm 1.3^{* *}$ \\
XK & $29.3 \pm 1.9$ & $24.0 \pm 1.8^{* *}$ & $20.5 \pm 1.3^{* *}$ & $25.3 \pm 2.0^{* *}$ \\
XT & $29.0 \pm 2.0$ & $19.3 \pm 0.9^{* *}$ & $16.9 \pm 0.8^{* *}$ & $22.0 \pm 0.7^{* *}$ \\
\hline
\end{tabular}

Values are presented as mean $\pm S E M, *$ Significant $(\mathrm{P}<0.05) * *$ Highly Significant $(\mathrm{P}<0.01)$

P - Profopol; XP - Xylazine-Propofol; XK - Xylazine-Ketamine; XT- Xylazine-Thiopentone 
During anaesthesia with $\mathrm{P}$ the heart rate increased significantly $(\mathrm{P}<0.01)$ five minutes after induction but insignificantly decreased at different stages. Previous studies in sheep and dogs revealed higher heart rate when propofol was used alone (Kim and Jang, 1999). All anaesthetic combinations decreased heart rate significantly $(\mathrm{P}<0.01)$ five minutes after induction, and it remained low during maximum depth of anaesthesia, and after recovery from anaesthesia with XK and XT, whereas heart rate returned almost to normal range after recovery from anaesthesia with XP. This corresponds well with the findings of Alkattan (2012) who reported deep sedation and bradycardia 1 - 3 minutes after injection of xylazine. This is due to decreased cardiac output caused by vagal activity. This result is similar to that of Ruffolo et al. (1993) where significant decrease in heart rate was found after administration of xylazine. Lumb and Jones (1996) observed decreased heart rate with thiopentone sodium. Significant decrease in systemic arterial blood pressure with a concurrent decrease in systemic vascular resistance after anaesthesia with XK was seen by Coulson et al. (1989). Increased heart rate with thiopentone and depression of the cardiac portion of the vagal centre has been recorded (Paddleford, 1999; Sogawa et al., 2012). Cardiovascular depression observed might be due to the effect of the $\alpha 2-$ agonist, decreases heart rate due to central and peripheral suppression of the sympathetic trunk, and its hypotensive effects (Lumb and Jones, 1996).

Table 2. Effects of anaesthetic agents on heart rate in pigs

\begin{tabular}{l|c|c|c|c}
\hline \multirow{2}{*}{ Groups } & \multicolumn{4}{c}{ Heart rate/minute } \\
\cline { 2 - 4 } & $\begin{array}{c}5 \text { min prior to } \\
\text { premedication }\end{array}$ & $\begin{array}{c}5 \text { min after } \\
\text { induction of } \\
\text { anaesthesia }\end{array}$ & $\begin{array}{c}\text { During maximum } \\
\text { depth of } \\
\text { anaesthesia }\end{array}$ & $\begin{array}{c}\text { After recovery } \\
\text { from anaesthesia }\end{array}$ \\
P & $95.8 \pm 4.0$ & $99.5 \pm 4.2^{* *}$ & $92.8 \pm 3.4$ & $93.8 \pm 2.7$ \\
XP & $97.5 \pm 2.5$ & $90.0 \pm 2.9^{* *}$ & $85.5 \pm 2.5$ & $96.3 \pm 2.0^{* *}$ \\
XK & $98.8 \pm 3.3$ & $90.0 \pm 2.9^{* *}$ & $85.8 \pm 3.8^{* *}$ & $93.0 \pm 2.7^{* *}$ \\
XT & $102.0 \pm 2.2$ & $91.8 \pm 2.0^{* *}$ & $86.8 \pm 2.8^{* *}$ & $96.5 \pm 1.7$ \\
\hline
\end{tabular}

Values are presented as mean SEM, *Significant $(\mathrm{P}<0.05){ }^{* *}$ Highly significant $(\mathrm{P}<0.01)$

P - Profopol; XP - Xylazine-Propofol; XK - Xylazine-Ketamine; XT- Xylazine-Thiopentone

Table 3. Effects of anaesthetic agents on rectal temperature in pigs

\begin{tabular}{l|c|c|c|c}
\hline \multirow{2}{*}{ Groups } & \multicolumn{4}{|c}{ Rectal temperature $\left({ }^{\circ} \mathrm{F}\right)$} \\
\cline { 2 - 4 } & $\begin{array}{c}5 \text { min prior to } \\
\text { premedication }\end{array}$ & $\begin{array}{c}5 \text { min after } \\
\text { induction of } \\
\text { anaesthesia }\end{array}$ & $\begin{array}{c}\text { During maximum } \\
\text { depth of } \\
\text { anaesthesia }\end{array}$ & $\begin{array}{c}\text { After recovery } \\
\text { from anaesthesia }\end{array}$ \\
$\mathrm{P}$ & $102.9 \pm 0.1$ & $102.4 \pm 0.2^{* *}$ & $101.8 \pm 0.1^{* *}$ & $102.6 \pm 0.2$ \\
$\mathrm{XP}$ & $102.6 \pm 0.4$ & $102.0 \pm 0.4^{* *}$ & $101.6 \pm 0.4^{* *}$ & $102.4 \pm 0.5^{* *}$ \\
$\mathrm{XK}$ & $102.3 \pm 0.4$ & $101.8 \pm 0.3^{*}$ & $101.5 \pm 0.3^{* *}$ & $102.0 \pm 0.3$ \\
$\mathrm{XT}$ & $102.8 \pm 0.3$ & $101.7 \pm 0.6^{*}$ & $101.2 \pm 0.7^{*}$ & $101.9 \pm 0.6$ \\
\hline
\end{tabular}

Values are presented as mean $\pm \mathrm{SEM}$, *Significant $(\mathrm{P}<0.05),{ }^{* *}$ Highly significant $(\mathrm{P}<0.01)$

P - Profopol; XP - Xylazine-Propofol; XK - Xylazine-Ketamine; XT- Xylazine-Thiopentone 
Rectal temperature decreased significantly $(\mathrm{P}<0.01)$ five minutes after induction, and during maximum depth of anaesthesia in $\mathrm{P}$ and $\mathrm{XP}$ after recovery from anaesthesia. $\mathrm{A}$ significant $(P<0.05)$ decrease in rectal temperature was observed five minutes after induction and during maximum depth of anaesthesia with XK and XT. Decrease in rectal temperature may be attributed to decrease in metabolic rate, and increase in heat loss (Paddleford, 1999) due to inhibition of skeletal muscle, peripheral vasodilatation and inactivation of the hypothalamic thermoregulatory centres (Kumar and Sharma, 1986; Sessler, 1994).

Slight to moderate salivation was observed in all pigs of groups $\mathrm{P}$ and XP. It has been reported that negligible salivation was observed with xylazine-propofol combination (Mirakhur et al., 1988; More et al., 1993). Profound salivation, urination, protrusion of tongue and shivering were observed with XT. These results correspond with Hofmeister et al. (2008) who reported protrusion of the tongue, which might be due to relaxation of pharyngeal muscles.

Table 6. Behaviour in pigs during anaesthesia

\begin{tabular}{l|c|c|c|c|c|c} 
Groups & Salivation & Lacrimation & Defecation & Urination & $\begin{array}{c}\text { Protrusion } \\
\text { of tongue }\end{array}$ & Shivering \\
$\mathrm{P}$ & - & - & - & - & - & - \\
$\mathrm{XP}$ & $+(2)$ & - & - & $+(2)$ & $+(1)$ & - \\
\hline $\mathrm{XK}$ & $+(2)$ & - & - & $+(1)$ & $+(1)$ & - \\
$\mathrm{XT}$ & $+(3)$ & - & - & $+(2)$ & $+(3)$ & $+(2)$ \\
\hline
\end{tabular}

+ Present; - Absent, Number indicates No. of pigs manifesting signs

P- Propofol; XP- Xylazine-Propofol; XK- Xylazine-Ketamine; XT- Xylazine-Thiopentone

\section{Conclusions}

Respiration and heart rates and rectal temperature are important during general anaesthesia of pigs. $\mathrm{P}$ and $\mathrm{XP}$ combination seems to be suitable for general anaesthesia, but XP is more suitable due to less effect on these clinical signs in pigs in Bangladesh.

\section{Acknowledgements}

The author is especially grateful to Dr. Md. Nure Alam Siddiki, Veterinary Surgeon, Taraganj, Rangpur and herd owner Mr. Prodip Horizone for their cooperation and encouragement throughout the study period.

\section{References}

Ajadi RA, Smith OF, Makinde AF, Adeleye OE 2008: Increasing ketamine do enhances the anaesthetic properties of ketamine-xylazine-midazolam combinations in growing pigs. Journal of the South African Veterinary Association 79 205-207.

Alkattan LM 2012: Analgesia and anesthesia with epidural Xylazine/Ketamine in donkeys. Diagnostic and Therapeutic Study 137- 44. 
Amarpal P, Kinjavdekar P, Aithal H, Pathak R, Pratap K, Singh V 2002: Effect of xylazine and medetomidine premedication of propofol anaesthesia in goats. Indian Journal of Animal Sciences 72 565-566.

Arras M, Autenried P, Rettich A, Spaeni D, Rulicke T 2001: Optimization of intraperitoneal injection anesthesia in mice: drugs, dosages, adverse effects and aesthesia depth. Computative Medicine 51 443-456.

Carroll GL, Hooper RN, Slater MR, Hartsfield SM, Matthews NS 1998: Detomidinebutorphanol-propofol for carotid artery translocation and castration or ovariectomy in goats. Veterinary Surgery 27 75-82.

Caulkett N 2003: Anaesthesia of ruminants. Large Animal Veterinary Rounds 3 1-6.

Coulson NM, Januszkiewicz AJ, Dodd KT, Ripple GR 1989: The cardiorespiratory effects of diazepam-ketamine and xylazine-ketamine anaesthetic combinations in sheep. Laboratory Animal Science 39 591-597.

Cullen LK, Reynoldson JA 1997: Effects of tiletamine Zolazepam premedication on propofol anaesthesia in dogs. Veterinary Record 140 363-366.

Gaertner DJ, Batchelder M, Hankenson FC, Hallman TM 2008: Anesthesia and analgesia for laboratory rodents, $2^{\text {nd }}$ edn. New York: Elsevier. pp. 239-297.

Glen JB, Hunter SC 1984: Pharmacology of an emulsion formulation of ICI 35 868. British Journal of Anaesthesia 56 617-626.

Gross DR 2009: Animal Models in Cardiovascular Research, Springer, New York, NY, USA.

Hall LW, Clarke KW, Trim CM 2001: Principles of sedation analgesia and premedication. In: Veterinary Anesthesia. 10thedn. Toronto, Ontario: Bailliere Tindall. pp. 75-107.

Hau J, Van Hoosier GL 2003: Handbook of Laboratory Animal Science. Volume 1-Essential Principles and Practices. CRC Press. pp. 556.

Hofmeister EH, Williams CO, Braun C, Moore PA 2008: Propofol versus thiopental: effects on peri-induction intraocular pressures in normal dogs. Veterinary Anaesthesia and Analgesia 35 275-281.

Huang YF, Upton RN, Gray EC, Grant C, Zheng D, Ludbrook GL 1997: The effects of short intravenous infusions of thiopentone on myocardial function, blood flow and oxygen consumption in sheep. Anaesthesia Intensive Care 25 627-633.

Kate W, Polly T 2000: Farm Animal Practice: Anaesthesia in sheep. In Practice 22 126-135.

Kim JW, Jang IH 1999: The effect of xylazine premedication on propofol anaesthesia in the dog. Korean Journal of Veterinary Clinics and Medicine 16 86-94.

Ko JC, Williams BL, Smith VL, McGrath CJ, Jacobson JD 1993: Comparison of Telazol, Telazol-ketamine, Telazol-xylazine, and Telazol-ketamine-xylazine as chemical restraint and anesthetic induction combination in pigs. Laboratory Animal Science $\mathbf{4 3}$ 476-480.

Lee JY, Jee HC, Jeong SM, Park CS, Kim MC 2010: Comparison of anaesthetic and cardiorespiratory effects of xylazine or medetomidine in combination with tiletamine/zolazepam in pigs. Veterinary Record 167 245-249. 
Lin HC, Purohit RC, Powe TA 1997: Anaesthesia in sheep with propofol or with xylazineketamine followed by halothane. Veterinary Surgery 26 247-252.

Lumb WV, Jones EW 1996: General anaesthesia. In: Veterinary Anaesthesia. Philadelphia, $3^{\text {rd }}$ edn. PA: Lea and Febiger. pp. 210-240.

Madrigal JL, Garcia-Bueno B, Caso JR, Perez-Nievas BG, Leza JC 2006: Stress-induced oxidative changes in brain. CNS Neurological Disorder Drug Targets 5 561-568.

Mama KR, Steffey EP, Pascoe PJ, Kollias BC 1998: Comparison of two techniques for total intravenous anesthesia in horses. American Journal of Veterinary Research 59 1292-1298.

Mirakhur KK, Sharma SN, Kumar VR 1988: Diazepam and thiopentone sodium anaesthesia in calves: evaluation of Cardio-respiratory dynamics, blood gases and acid base status. Journal of Veterinary Medicine 35 775-784.

More DB, Bhokre AP, Panchbhal, Usturge SM 1993: Experimental evaluation of diazepam xylazine ketamine anaesthesia in calves. Indian Veterinary Journal 70 145-147.

Murrell J 2007: Choice of premedicants in cats and dog. In Practice 29 100-106.

Paddleford RR 1999: Preanesthetic agents. In: Manual of Small Animal Anaesthesia. Churchill Living stone. New York, USA, pp. 12-30.

Pypendop B, Serteyn D, Verstegen J 1996: Hemodynamic effects of medetomidinemidazolam-butorphanol combinations and reversibility by atipamezole in dogs. American Journal of Veterinary Research 57 724-730.

Ramakrishna O, Murthy DK, Nigam JM 1981: Ketamine anaesthesia in buffalo calves. Indian Veterinary Journal 58 503-505.

Ribeiro LM, Ferreira DA, Bras S, Castro A, Nunes CA, Amorim P, Antunes LM 2009: Correlation between clinical signs of depth of anaesthesia and cerebral state index responses in dogs during induction of anaesthesia with propofol. Research in Veterinary Science 87 287-291.

Riebold TW, Geiser DR, Globe DO 1995: Principles and techniques of anaesthesia. In: Large Animal Anesthesia, $2^{\text {nd }}$ edn. Iowa State University Press, Ames. pp. 14-264.

Ruffolo RR, Jr Nichols AJ, Stade LJ, Hieble JP 1993: Pharmacologic and therapeutic applications of alpha 2-adrenoceptor subtypes. Annual Review of Pharmacology and Toxicology 33 243-279.

Schifilliti D, Grasso G, Conti A, Fodale V 2010: Anaesthetic-related neuroprotection: intravenous or inhalational agents? CNS Drugs 24 893-907.

Sessler DL 1994: Temperature Monitoring. In: Anaesthesia. New York, Churchill, Livingston. pp. 1363-1382.

Silva A, Ferreira DA, Venancio C, Souza AP, Antunes LM 2011: Performance of electroencephalogram-derived parameters in prediction of depth of anaesthesia in a rabbit model. British Journal of Anaesthesia 106 540-547. 
Sogawa N, Hazehara Y, Kunitomo M, Morita Y, Yoo B, Ohyama K, Sogawa C, Kitayama S 2012: Age-dependent changes in the susceptibility to thiopental anesthesia in mice: analysis of the relationship to the functional expression of GABA transporter. Pharmacology, Biochemistry and Behavior 103 267-272.

Tacheci I, Kvetina J, Kunes M, Pavlík M, Kopacova M, Cerny V, Rejchrt S, Varajil JE, Bures J 2013: The effect of general anaesthesia on gastric myoelectric activity in experimental pigs. BMC Gastroenterology 1348.

Thurmon JC, Smith GW 2007: Pigs. In Lumb and Jones' Veterinary Anesthesia and Analgesia. 4th edn. Eds WJ Tranquilli, JC Thurmon, KA Grimm. Blackwell Publishing Co. pp. 747-763.

Toyama H, Ichisea M, Liowa JS, Vinesa DC, Senecaa NM, Modella KJ, Seidelb J, Greenb, MV, Innisa RB 2004: Evaluation of anesthesia effects on [18F]18F-FDG uptake in mouse brain and heart using small animal PET. Nuclear Medicine and Biology 31 251-256.

Watkins SB, Hall LW, Clarke KW 1987: Propofol as an intravenous anaesthetic agent in dogs. Veterinary Record 120 326-329.

Wessler B, Madias C, Pandian N, Link MS 2011: Short-term effects of ketamine and isoflurane on left ventricular ejection fraction in an experimental pigs model. ISRN Cardiology 58 2658-2665. 